Article

\title{
Analyzing the Performance of a Dual Loop Organic Rankine Cycle System for Waste Heat Recovery of a Heavy-Duty Compressed Natural Gas Engine
}

\author{
Baofeng Yao ${ }^{1, *}$, Fubin Yang ${ }^{1}$, Hongguang Zhang ${ }^{1}$, Enhua Wang ${ }^{2}$ and Kai Yang ${ }^{1}$ \\ 1 College of Environmental and Energy Engineering, Beijing University of Technology, \\ Pingleyuan No.100, Beijing 100124, China; E-Mails: yangfubinnuc@163.com (F.Y.); \\ zhanghongguang@bjut.edu.cn (H.Z.); ykai104@163.com (K.Y.) \\ 2 State Key Laboratory of Automotive Safety and Energy, Tsinghua University, Qinghuayuan, \\ Beijing 100084, China; E-Mail: wangenhua@tsinghua.org.cn \\ * Author to whom correspondence should be addressed; E-Mail: yaobf@bjut.edu.cn; \\ Tel.: +86-10-6739-2469; Fax: +86-10-6739-2774.
}

External Editor: Roberto Capata

Received: 8 September 2014; in revised form: 10 October 2014 / Accepted: 15 October 2014 / Published: 21 November 2014

\begin{abstract}
A dual loop organic Rankine cycle (DORC) system is designed to recover waste heat from a heavy-duty compressed natural gas engine (CNGE), and the performance of the DORC-CNGE combined system is simulated and discussed. The DORC system includes high-temperature (HT) and low-temperature (LT) cycles. The HT cycle recovers energy from the exhaust gas emitted by the engine, whereas the LT cycle recovers energy from intake air, engine coolant, and the HT cycle working fluid in the preheater. The mathematical model of the system is established based on the first and second laws of thermodynamics. The characteristics of waste heat energy from the CNGE are calculated according to engine test data under various operating conditions. Moreover, the performance of the DORC-CNGE combined system is simulated and analyzed using R245fa as the working fluid. Results show that the maximum net power output and the maximum thermal efficiency of the DORC system are $29.37 \mathrm{~kW}$ and $10.81 \%$, respectively, under the rated power output condition of the engine. Compared with the original $\mathrm{CNG}$ engine, the maximum power output increase ratio and the maximum brake specific fuel consumption improvement ratio are $33.73 \%$ and $25 \%$, respectively, in the DORC-CNGE combined system.
\end{abstract}


Keywords: compressed natural gas (CNG) engine; waste heat recovery; dual loop organic Rankine cycle; various operating conditions

\section{Introduction}

At present, petroleum resources are being rapidly depleted worldwide as energy consumption demand further increases with the development of human society. A growing number of strict emission rules are also being formulated and implemented to reduce the environmental impact of petroleum consumption. Given these situations, alternative energy vehicles are promoted with the advantages of relieving stress on petroleum consumption and reducing harmful emissions. Natural gas is regarded as one of the most important alternative fuels because of its abundant reserves, low cost, and low emissions. In addition, both compressed natural gas (CNG) and liquefied natural gas (LNG) engines are widely used in commercial vehicles, power-generating systems, and construction machineries. However, compared with gasoline and diesel engines, natural gas engines experience power loss and are less thermal efficient [1]. Thus, natural gas engines may waste high amounts of fuel combustion power via the exhaust and coolant systems. Investigating waste heat recovery (WHR) of natural gas engines is therefore valuable to improve the power output and thermal efficiency of these engines.

The organic Rankine cycle (ORC) has been implemented widely in various fields, such as in low-grade WHR, waste heat power-generating systems [2], industrial waste heat [3], geothermal energy [4,5], and solar energy [6,7]. Different heat resources have varying characteristics; meanwhile, numerous organic working fluids with different thermophysical and environmental properties are available in practical applications. Considerable research has been conducted to determine appropriate organic working fluids for a given heat resource. Hung et al., indicated that wet working fluids with extremely steep saturated vapor curves in the $T-s$ diagram generally perform better than dry working fluids [8]. Wang et al., selected nine pure organic working fluids according to their physical and chemical properties; among these, R245fa and R245ca are found to be the most environment friendly for engine WHR applications [9]. Toffolo et al., assessed the performance of two working fluids, namely, isobutane and R134a, in temperatures ranging from 130 to $180{ }^{\circ} \mathrm{C}$. The results showed that the maximum power output of $\mathrm{R} 134 \mathrm{a}$ is higher than that of isobutene in all temperature ranges [10]. Moreover, similar to the traditional Rankine cycle, the ORC has several structures, which include simple, regenerative, and reheat ORCs. The analysis and optimization of different ORC structures are found in previous research [11-13].

Waste heat resources in internal combustion engines (ICEs) are low- or medium-grade energy. Applying the ORC system to ICEs is reasonable because it is suitable for the temperature regions of the waste heat resources of ICEs. Recently, works in this field have been conducted actively, and the results show that engine waste heat recovery through the ORC system can potentially improve the total power output and fuel consumption performance of ICEs. Srinivasan et al., analyzed the WHR performance of a dual fuel low-temperature combustion engine through the ORC system [14]. Boretti et al., investigated the exhaust and coolant heat recovery performance of R $245 \mathrm{fa}$ ORCs in a hybrid passenger car with a naturally aspirated gasoline engine [15]. Wang et al., evaluated the 
improvement in efficiency of a gasoline engine through experiments and numerical simulations based on the steam Rankine cycle. The test results indicated that the engine can save up to $34 \%$ fuel under several operating conditions [16].

In particular, the ORC is regarded as an effective means to recover waste heat from ICEs. However, previous studies have mostly focused on gasoline [17] and diesel engines [18-20], and only a few of these studies have been conducted for natural gas engines. Given that the development of alternative energy is a worldwide agreement, the present work is performed on a heavy-duty CNG engine platform for commercial vehicles. A WHR system is designed based on the dual loop ORC (DORC) to recover waste heat energy from exhaust gas, intake air, and engine coolant. First, the system is schemed, described, and numerically modeled based on DORC theory and the features of the $\mathrm{CNG}$ engine. Second, the characteristics of waste heat from $\mathrm{CNG}$ engines, which function as high-temperature heat sources of the DORC WHR system, are calculated according to engine test data under various operating conditions. Subsequently, the thermal efficiency, power output increase ratio (POIR), and brake specific fuel consumption (BSFC) improvement ratio (BIR) of the DORC-CNGE combined system are calculated to evaluate its WHR performance according to the simulation results.

\section{Description and Modeling of the DORC System}

\subsection{Description}

A heavy-duty CNG engine mainly generates waste heat from exhaust gas, intake air, and engine coolant. A DORC system for recovering waste heat of CNG engines is designed, as shown in Figure 1. The figure shows that the system is composed of both HT (red line) and LT (green line) cycles. Given that the temperature of exhaust gas is higher than those of other waste heat resources, the HT cycle is used to recover waste heat energy from exhaust gas, whereas the LT cycle is used to recover waste heat energy from intake air, engine coolant, and the HT cycle working fluid in the condenser. As shown in Figure 1, the HT cycle consists of evaporator 1, expander 1, generator 1, pump 1, and a preheater; whereas the LT cycle consists of evaporator 2, expander 2, generator 2, pump 2, a preheater, a condenser, and an intercooler. The LT loop is coupled to the HT loop via the preheater, which is used as the condenser for the HT loop. Otherwise, the output power of the two expanders is used to produce electricity. First, the transmission of electrical energy is more flexible than that of mechanical energy. Second, an increasing number of electrical devices are currently installed in vehicles, and thus, vehicles require more electric power than before. Meeting the electricity demands of vehicles can reduce engine load. Third, this technical proposal can also flexibly satisfy the requirements of hybrid electric vehicles.

The working principle of the DORC system is described as follows. In the HT cycle, the liquid working fluid from the preheater is compressed by pump 1 until it achieves the supercooled state, and then the fluid transforms into saturated vapor by absorbing heat energy from the exhaust gas of the CNG engine in evaporator 1 . The saturated working fluid vapor expands through expander 1 and rotates this expander. This rotation can drive generator 1, and thus, produce electricity, which can be a useful power output. Subsequently, the exhaust steam is cooled by the LT cycle working fluid in the preheater. This steam transforms into a saturated liquid state, which moves into the next circuit. In the 
LT cycle, the liquid working fluid is also compressed by pump 2 until it reaches a supercooled state. The supercooled liquid absorbs the heat energy of the intake air in the intercooler, which reduces the supercooled degree. The working fluid continues to absorb the heat energy of the steam exhaust of the HT cycle working fluid in the preheater, and then transforms into a two-phase gas-liquid state. After the working fluid is heated to achieve a saturated vapor state by the engine coolant in evaporator 2 , the fluid expands through expander 2 and rotates this expander, which drives generator 2 to produce electricity. Finally, the exhaust steam is condensed into a saturated liquid state in the condenser, and then, it flows into the next circuit.

Figure 1. The schematic of the dual loop organic Rankine cycle (DORC) system.

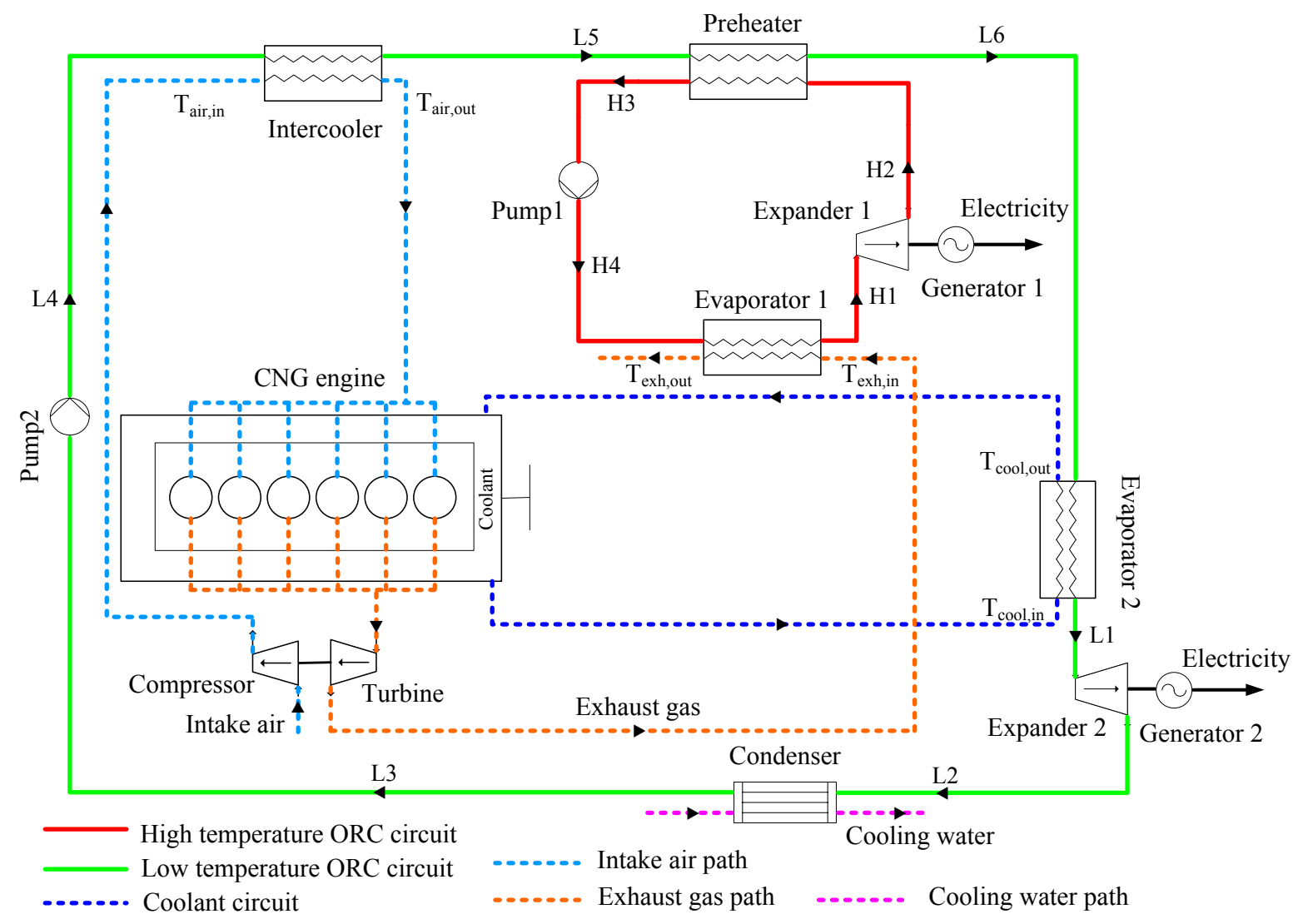

\subsection{Modeling}

Based on the first and second laws of thermodynamics, the thermodynamic model of the aforementioned DORC system is established using MATLAB software (Mathworks, Natick, MA, USA). The selection of working fluid is critical to optimize the performance of the ORC system. An appropriate working fluid should not only ensure a stable operation and an efficient ORC system but should also satisfy the requirements of usage safety and environmental protection performance. According to Wang [9], R245fa can satisfy the general requirements for an appropriate working fluid for engine WHR applications. Hence, R245fa is used as the working fluid in the present work. The main properties of this fluid are listed in Table 1. The thermodynamic properties of this working fluid are evaluated using REFPROP 8.0 program developed by the National Institute of Standards and Technology of the United States [21]. 
Table 1. Main properties of working fluid R245fa.

\begin{tabular}{cccc}
\hline Working Fluid & Molecular Formula & $\begin{array}{c}\text { Molecular Weight } \\
(\mathbf{k g} / \mathbf{k m o l})\end{array}$ & $\begin{array}{c}\text { Critical Temperature } \\
(\mathbf{K})\end{array}$ \\
\hline $\mathrm{R} 245 \mathrm{fa}$ & $\mathrm{CHF}_{2} \mathrm{CH}_{2} \mathrm{CF}_{3}$ & 134.05 & 427.16 \\
\hline Critical Pressure (MPa) & Boiling temperature (K) & $\boldsymbol{O D P}$ & $\boldsymbol{G W P}(\mathbf{1 0 0}$ years) \\
\hline 3.65 & 288.29 & 0 & 950 \\
\hline
\end{tabular}

\subsubsection{HT Cycle Process}

The $T$-s diagram of the HT cycle is shown in Figure 2.

Figure 2. $T-s$ diagram of the high-temperature (HT) cycle.

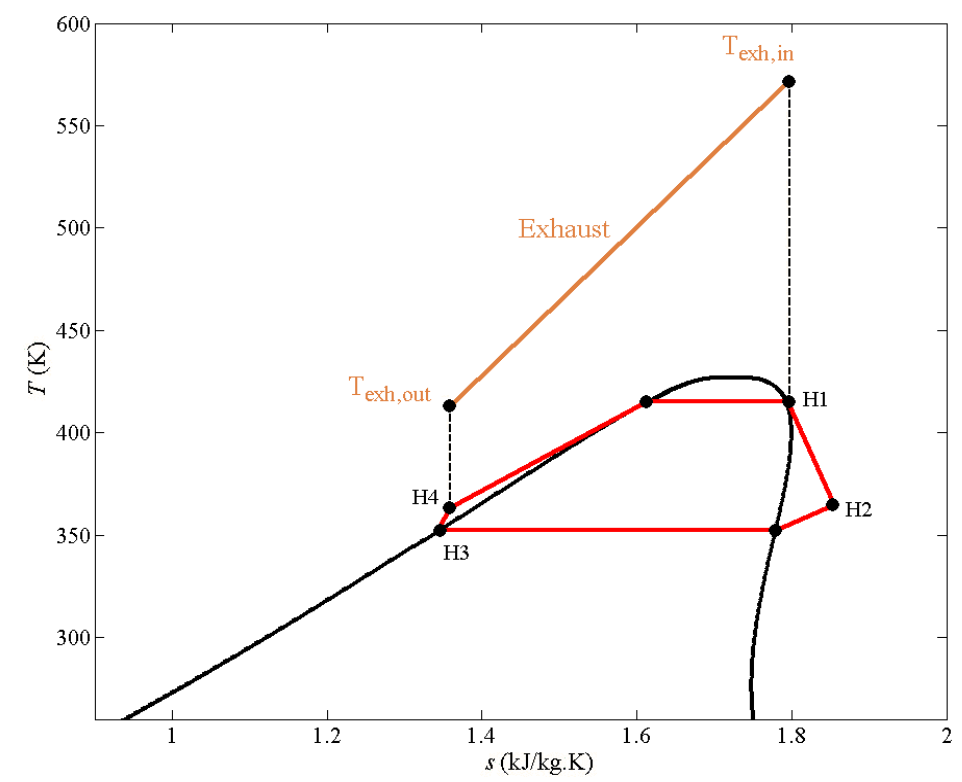

Pump phase (the saturated liquid state $\mathrm{H}_{3}-$ the supercooled liquid state $\mathrm{H}_{4}$ ):

The power output of pump 1, which is used to compress the working fluid and its exergy destruction rate during pumping, is expressed through Equations (1) and (2), as follows:

$$
\begin{aligned}
& \dot{W}_{\mathrm{p} 1}=\dot{m}_{\mathrm{H}}\left(h_{\mathrm{H} 4}-h_{\mathrm{H} 3}\right) \\
& \dot{I}_{\mathrm{p} 1}=T_{0} \dot{m}_{\mathrm{H}}\left(s_{\mathrm{H} 4}-s_{\mathrm{H} 3}\right)
\end{aligned}
$$

Evaporator phase (the supercooled liquid state $\mathrm{H}_{4}-$ the saturated vapor state $\mathrm{H}_{1}$ ):

The heat transfer rate between the working fluid and the exhaust gas in evaporator 1, as well as the exergy destruction rate of the working fluid during evaporation, is calculated through Equations (3) and (4), as follows:

$$
\begin{gathered}
\dot{Q}_{\mathrm{e} 1}=c_{\mathrm{p}, \mathrm{exh}} \dot{m}_{\mathrm{exh}}\left(T_{\mathrm{exh}, \mathrm{n}}-T_{\mathrm{exh}, \mathrm{out}}\right)=\dot{m}_{\mathrm{H}}\left(h_{\mathrm{H} 1}-h_{\mathrm{H} 4}\right) \\
\dot{I}_{\mathrm{e} 1}=T_{0} \dot{m}_{\mathrm{H}}\left[\left(s_{\mathrm{H} 1}-s_{\mathrm{H} 4}\right)-\frac{h_{\mathrm{H} 1}-h_{\mathrm{H} 4}}{T_{\mathrm{HTH}}}\right]
\end{gathered}
$$


where the temperature of the high-temperature heat source in the HT cycle is calculated through Equations (5) and (6), as follows:

$$
\begin{gathered}
T_{\mathrm{HTH}}=T_{\mathrm{H} 1}+\Delta T_{\mathrm{HTH}} \\
\Delta T_{\mathrm{HTH}}=\frac{\left(T_{\text {exhin }}-T_{\mathrm{H} 1}\right)-\left(T_{\text {exhout }}-T_{\mathrm{H} 4}\right)}{\ln \frac{T_{\text {exhin }}-T_{\mathrm{H} 1}}{T_{\text {exhout }}-T_{\mathrm{H} 4}}}
\end{gathered}
$$

According to Bahadori [22], the internal surface of exhaust pipes and evaporators can corrode if exhaust gas temperature drops below the acid dew point. Hence, exhaust gas temperature at the outlet of evaporator 1 is set to $427.15 \mathrm{~K}$, and exhaust gas mass flow rate and temperature at the inlet of evaporator 1 are obtained through the engine test.

Expander phase (the saturated vapor state $\mathrm{H}_{1}$-the superheated vapor state $\mathrm{H}_{2}$ ):

The power output of expander 1 and the exergy destruction rate of the working fluid during expansion in expander 1 are determined via Equations (7) and (8), as follows:

$$
\begin{aligned}
& \dot{W}_{\exp 1}=\dot{m}_{\mathrm{H}}\left(h_{\mathrm{H} 1}-h_{\mathrm{H} 2}\right) \\
& \dot{I}_{\exp 1}=T_{0} \dot{m}_{\mathrm{H}}\left(s_{\mathrm{H} 2}-s_{\mathrm{H} 1}\right)
\end{aligned}
$$

Preheater phase (the superheated vapor state $\mathrm{H}_{2}$-the saturated liquid state $\mathrm{H}_{3}$ ):

The heat rejection rate of the working fluid during condensation in the HT cycle can be calculated through Equation (9), as follows:

$$
\dot{Q}_{\mathrm{H}, \mathrm{pre}}=\dot{m}_{\mathrm{H}}\left(h_{\mathrm{H} 2}-h_{\mathrm{H} 3}\right)
$$

\subsubsection{LT Cycle Process}

The $T-s$ diagram of the LT cycle is shown in Figure 3.

Figure 3. $T$-s diagram of the low-temperature (LT) cycle.

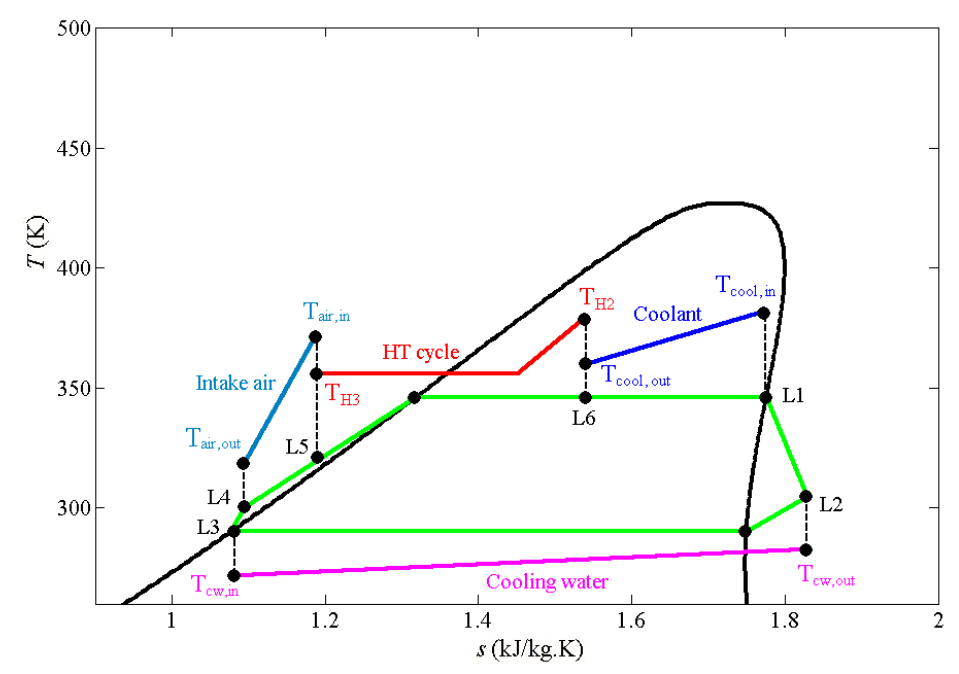


Pump phase (the saturated liquid state $\mathrm{L}_{3}-$ the supercooled liquid state $\mathrm{L}_{4}$ ):

The power output of pump 2, which is used to compress the working fluid and the exergy destruction rate of the working fluid during pumping, is determined through Equations (10) and (11), as follows:

$$
\begin{gathered}
\dot{W}_{\mathrm{p} 2}=\dot{m}_{\mathrm{L}}\left(h_{\mathrm{L} 4}-h_{\mathrm{L} 3}\right) \\
\dot{I}_{\mathrm{p} 2}=T_{0} \dot{m}_{\mathrm{L}}\left(s_{\mathrm{L} 4}-s_{\mathrm{L} 3}\right)
\end{gathered}
$$

Intercooler phase (a deeper supercooled liquid state L4-a lighter supercooled liquid state L5):

The heat transfer rate between the working fluid and the intake air in the intercooler, as well as the exergy destruction rate during the flow of the working fluid through the intercooler, is calculated through Equations (12) and (13), as follows:

$$
\begin{gathered}
\dot{Q}_{\mathrm{int}}=c_{\mathrm{p}, \text { air }} \dot{m}_{\mathrm{air}}\left(T_{\mathrm{air}, \text { in }}-T_{\mathrm{air}, \mathrm{out}}\right)=\dot{m}_{\mathrm{L}}\left(h_{\mathrm{L} 5}-h_{\mathrm{L} 4}\right) \\
\dot{I}_{\mathrm{int}}=T_{0} \dot{m}_{\mathrm{L}}\left[\left(s_{\mathrm{L} 5}-s_{\mathrm{L} 4}\right)-\frac{h_{\mathrm{L} 5}-h_{\mathrm{L} 4}}{T_{\mathrm{int}, \mathrm{HS}}}\right]
\end{gathered}
$$

where the temperature of the heat source in the intercooler is determined through Equations (14) and (15), as follows:

$$
\begin{gathered}
T_{\text {int,HS }}=T_{\mathrm{L} 5}+\Delta T_{\text {int }} \\
\Delta T_{\text {int }}=\frac{\left(T_{\text {air,in }}-T_{\mathrm{L} 5}\right)-\left(T_{\text {air,out }}-T_{\mathrm{L} 4}\right)}{\ln \frac{T_{\text {air,in }}-T_{\mathrm{L} 5}}{T_{\text {air,out }}-T_{\mathrm{L} 4}}}
\end{gathered}
$$

Preheater phase (the supercooled liquid state L5-the gas-liquid two-phase state L6): $_{6}$

The heat transfer rate of the working fluids between the LT and HT cycles in the preheater, as well as the exergy destruction rate during preheating, is determined through Equations (16) and (17), as follows:

$$
\begin{gathered}
\dot{Q}_{\mathrm{L}, \mathrm{pre}}=\dot{m}_{\mathrm{L}}\left(h_{\mathrm{L} 6}-h_{\mathrm{L} 5}\right)=\dot{m}_{\mathrm{H}}\left(h_{\mathrm{H} 2}-h_{\mathrm{H} 3}\right) \\
\dot{I}_{\text {pre }}=T_{0} \dot{m}_{\mathrm{H}}\left(s_{\mathrm{H} 3}-s_{\mathrm{H} 2}\right)+T_{0} \dot{m}_{\mathrm{L}}\left(s_{\mathrm{L} 6}-s_{\mathrm{L} 5}\right)
\end{gathered}
$$

Evaporator phase (the gas-liquid state $\mathrm{L}_{6}$-the saturated vapor state $\mathrm{L}_{1}$ ):

The heat absorption rate of the working fluid in evaporator 2 and the exergy destruction rate during evaporation are determined through Equations (18) and (19), as follows:

$$
\begin{gathered}
\dot{Q}_{\mathrm{e} 2}=\dot{m}_{\mathrm{L}}\left(h_{\mathrm{L} 1}-h_{\mathrm{L} 6}\right)=\varphi_{\text {coo }} \dot{Q}_{\text {cool } 1} \\
\dot{I}_{\mathrm{e} 2}=T_{0} \dot{m}_{\mathrm{L}}\left[\left(s_{\mathrm{L} 1}-s_{\mathrm{L} 6}\right)-\frac{h_{\mathrm{L} 1}-h_{\mathrm{L} 6}}{T_{\mathrm{HTL}}}\right]
\end{gathered}
$$


The heat rejection rate of the engine coolant is calculated according to the engine test data. The temperature of the high-temperature heat source in the LT cycle is determined through Equations (20) and (21), as follows:

$$
\begin{aligned}
& T_{\mathrm{HTL}}=T_{\mathrm{L} 1}+\Delta T_{\mathrm{HTL}}
\end{aligned}
$$

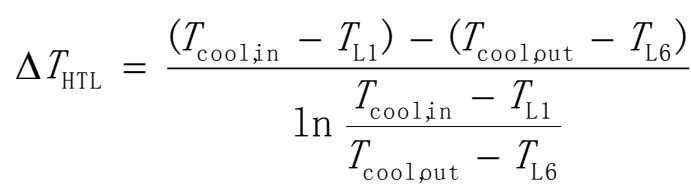

Expander phase (the saturated vapor state $\mathrm{L}_{1}-$ the superheated vapor state $\mathrm{L}_{2}$ ):

The power output of expander 2 and the exergy destruction rate during expansion are determined through Equations (22) and (23), as follows:

$$
\begin{aligned}
& \dot{W}_{\exp 2}=\dot{m}_{\mathrm{L}}\left(h_{\mathrm{L} 1}-h_{\mathrm{L} 2}\right) \\
& \dot{I}_{\exp 2}=T_{0} \dot{m}_{\mathrm{L}}\left(s_{\mathrm{L} 2}-s_{\mathrm{L} 1}\right)
\end{aligned}
$$

Condenser phase (the superheated vapor state $\mathrm{L}_{2}-$ the saturated liquid state $\mathrm{L}_{3}$ ):

The heat rejection rate of the working fluid in the LT cycle and the exergy destruction rate during condensation are calculated through Equations (24) and (25), as follows:

$$
\begin{gathered}
\dot{Q}_{\text {con }}=\dot{m}_{\mathrm{L}}\left(h_{\mathrm{L} 2}-h_{\mathrm{L} 3}\right) \\
\dot{I}_{\text {con }}=T_{0} \dot{m}_{\mathrm{L}}\left[\left(s_{\mathrm{L} 3}-s_{\mathrm{L} 2}\right)-\frac{h_{\mathrm{L} 3}-h_{\mathrm{L} 2}}{T_{\mathrm{LTL}}}\right]
\end{gathered}
$$

where the temperature of the low-temperature heat source in the LT cycle is determined through Equations (26) and (27), as follows:

$$
\begin{gathered}
T_{\mathrm{LTL}}=T_{\mathrm{L} 3}-\Delta T_{\mathrm{LTL}} \\
\Delta T_{\mathrm{LTL}}=\frac{\left(T_{\mathrm{L} 2}-T_{\mathrm{cw}, \text { out }}\right)-\left(T_{\mathrm{L} 3}-T_{\mathrm{cw}, \text { in }}\right)}{\ln \frac{T_{\mathrm{L} 2}-T_{\mathrm{cw}, \text { out }}}{T_{\mathrm{L} 3}-T_{\mathrm{cw}, \text { in }}}}
\end{gathered}
$$

\subsubsection{Performance Parameters of the DORC System}

The net output power of the HT cycle is calculated through Equation (28), as follows:

$$
\dot{W}_{\mathrm{H}, \mathrm{net}}=\dot{W}_{\exp 1}-\dot{W}_{\mathrm{p} 1}
$$

The net output power of the LT cycle is calculated through Equation (29), as follows:

$$
\dot{W}_{\mathrm{L}, \mathrm{net}}=\dot{W}_{\exp 2}-\dot{W}_{\mathrm{p} 2}
$$

The net output power of the DORC system is calculated through Equation (30), as follows:

$$
\dot{W}_{\text {DORC, net }}=\dot{W}_{\mathrm{H}, \text { net }}+\dot{W}_{\mathrm{L}, \text { net }}
$$

The exergy destruction rate of the DORC system is calculated through Equation (31), as follows: 


$$
\dot{I}=\dot{I}_{\mathrm{p} 1}+\dot{I}_{\mathrm{e} 1}+\dot{I}_{\mathrm{exp} 1}+\dot{I}_{\mathrm{pre}}+\dot{I}_{\mathrm{p} 2}+\dot{I}_{\mathrm{int}}+\dot{I}_{\mathrm{e} 2}+\dot{I}_{\mathrm{exp} 2}+\dot{I}_{\mathrm{con}}
$$

Furthermore, the thermal efficiencies of the DORC, POIR, and BIR of the engine are selected to evaluate the performance of the DORC-CNGE combined system. The three parameters can be calculated through the following equations.

The thermal efficiency of the DORC system is determined through Equation (32), as follows:

$$
\eta_{\mathrm{w}}=\frac{\dot{W}_{\mathrm{DORC}, \text { net }}}{\dot{Q}_{\mathrm{w}}} \times 100 \%
$$

where the total recovered waste heat energy in the DORC system is calculated through Equation (33), as follows:

$$
\dot{Q}_{\mathrm{w}}=\dot{Q}_{\mathrm{exh}}+\dot{Q}_{\mathrm{int}}+\dot{Q}_{\mathrm{cool}}
$$

The POIR of the CNG engine to the DORC-CNGE combined system is expressed through Equation (34), as follows:

$$
\mathrm{POIR}=\frac{\dot{W}_{\text {DORC,net }}}{\dot{W}_{\text {eng,eff }}} \times 100 \%
$$

The BSFC of the DORC-CNGE combined system is calculated through Equation (35), as follows:

$$
b_{c s}=\frac{\dot{F}}{\dot{W}_{\text {eng,eff }}+\dot{W}_{\text {DORC,net }}} \times 1000
$$

The BIR of the $\mathrm{CNG}$ engine to the DORC-CNGE combined system is calculated through Equation (36), as follows:

$$
\mathrm{BIR}=\frac{b_{\text {eng }}-b_{\mathrm{cs}}}{b_{\text {eng }}} \times 100 \%
$$

In the present work, several hypotheses of the operating conditions of the DORC system are set as follows:

(1) The system works under steady state. Pressure loss and heat rejection are disregarded.

(2) The isentropic efficiency of the expanders is set to 0.7 , and the isentropic efficiency of the pumps is set to 0.65 . These efficiencies are slightly high but achievable. A high value is chosen to help analyze the potential maximum power generated by the ORC [18].

(3) The condensing temperature of the HT cycle is set to $353.15 \mathrm{~K}$, and the ambient temperature is set to $291.15 \mathrm{~K}$.

(4) To ensure a suitable heat transfer temperature difference, the evaporating temperature of the LT cycle is set to $348.15 \mathrm{~K}$ because the temperature of the engine coolant in evaporator 2 is maintained at $363.15 \mathrm{~K}$, and the condensing temperature of the LT cycle is set to $293.15 \mathrm{~K}$.

(5) A small part of the heat energy in the engine coolant can be recovered, while a large part of the heat energy dissipates into the environment [20,23]; thus, the heat transfer efficiency of evaporator 2 is set to 0.3 in the present model. 


\section{Performance and Waste Heat Characteristics of the CNG Engine}

Discussing the performance and waste heat characteristics of the $\mathrm{CNG}$ engine is important to optimize a matching ORC system and achieve efficient WHR from these engines. In the present work, an electronically controlled, heavy-duty, and lean-burn CNG engine is selected and tested under various operating conditions. The main specifications of the CNG engine are listed in Table 2.

Table 2. The main specifications of the compressed natural gas $(\mathrm{CNG})$ engine.

\begin{tabular}{cc}
\hline Items & Parameters \\
\hline Cylinder arrangement & in-line \\
Cylinder number & 6 \\
Stroke and cylinder bore & $114 \mathrm{~mm} \times 144 \mathrm{~mm}$ \\
Stroke number & 4 \\
Displacement & $8.8 \mathrm{~L}$ \\
Cooling type & Water cooling \\
Aspiration & Turbocharged and Intercooled \\
Rated power (Rated speed) & $210 \mathrm{~kW}(2200 \mathrm{r} / \mathrm{min})$ \\
Maximum torque (speed) & $1120 \mathrm{~N} \cdot \mathrm{m}(1400 \mathrm{r} / \mathrm{min})$ \\
Fuel supply & Port fuel injection \\
Ignition type & Spark ignition \\
\hline
\end{tabular}

The engine speed for the test varies from 800 to $2200 \mathrm{r} / \mathrm{min}$ with an interval of $100 \mathrm{r} / \mathrm{min}$. For each selected engine speed, 10 load conditions, which range from full load to minimum stable load condition, are chosen. Brake output power, fuel consumption parameters, intake/exhaust parameters, and coolant parameters are acquired under each operating condition with a given engine speed and torque.

The performance and waste heat characteristics of the CNG engine are expressed by the distribution of the test and calculated parameters on the operating condition map that is coordinated by engine speed and engine torque in this study.

Based on engine test data, the distributions of the BSFC and the brake output power of the CNG engine under different engine speeds and torques are plotted in Figure 4. The BSFC is expressed using colored contour bands with black contour lines, and engine performances with the same BFSC are found on the same colored contour band or black contour line. Under low load conditions, the BSFC is slightly influenced by engine speed, but under medium and high load conditions, the BSFC increases after decreasing as engine speed increases. However, the BSFC evidently and monotonously increases as engine torque increases. The zone where BSFC is lower than $200 \mathrm{~g} /(\mathrm{kW} \cdot \mathrm{h})$ is located in engine speed conditions ranging from 1200 to $1700 \mathrm{r} / \mathrm{min}$ and in engine torque conditions ranging from $900 \mathrm{~N} \cdot \mathrm{m}$ to the maximum value. As shown in the plot, the engine performs with the same brake output power on the same green contour line. Brake output power rises as engine speed and engine torque increase, and when the maximum value of the brake output is $212 \mathrm{~kW}$ under the rated power condition.

Exhaust temperature and exhaust mass flow, which are acquired after the turbine, are plotted in Figure 5 according to engine test data. 
Figure 4. The distribution of BSFC and brake output power of the CNG engine.

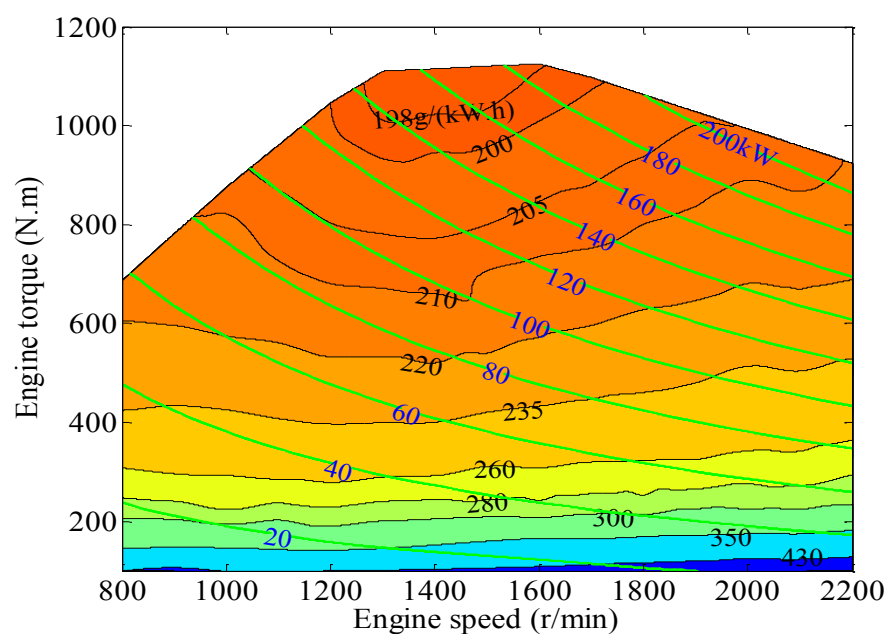

Figure 5. (a) The distributions of the exhaust temperature of the CNG engine; (b) The distributions of the exhaust mass flow rate of the $\mathrm{CNG}$ engine.

(a)

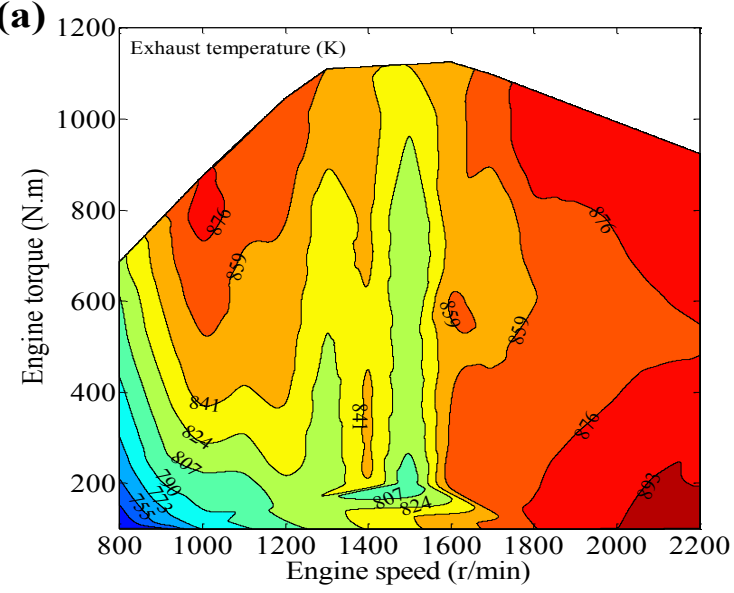

(b)

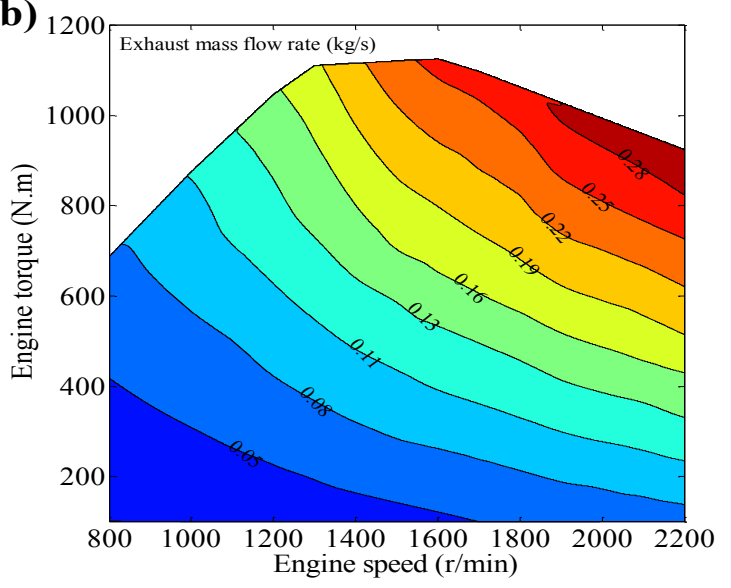

As shown in Figure 5a, exhaust temperature is relatively low under low speed-low torque conditions, and relatively high under both low speed-high torque and high speed conditions. In addition, the highest exhaust temperature is $910 \mathrm{~K}$ under high speed-low torque condition. Moreover, exhaust temperature rises as engine torque increases in the low-speed area, but the trend is complex in the area with medium- and high-speed conditions. The complex trend may be attributed to the control strategy of the turbocharger. As shown in Figure 5b, exhaust mass flow rate increases in the entire engine test region when engine speed and engine torque increase because the throttle-equipped engines consume a growing amount of intake air and fuel masses.

In Figure 6, the distributions of several engine input and output energy are plotted under various engine speed and engine torque conditions.

The distribution of fuel combustion power under different operating conditions is shown in Figure 6a. As shown in the figure, the engine consumes more fuel to produce more energy as engine speed and engine torque increase. The maximum fuel combustion power is $556 \mathrm{~kW}$ under the rated output power condition. Similarly, in Figure 6b,c, the effective engine power output and exhaust energy flow rate increase as engine speed and engine torque increase. In addition, the maximum exhaust energy flow 
rate is $154 \mathrm{~kW}$ under the rated output power condition. The distribution of the waste heat flow rate of the engine coolant under different operating conditions is shown in Figure $6 \mathrm{~d}$. The waste heat flow rate of the engine coolant has a relatively low energy under low speed-low torque condition and a relatively high energy under high speed-high torque condition. However, the trend is not as monotonous as that of fuel combustion power. The maximum waste heat flow rate of the engine coolant is $86 \mathrm{~kW}$ under all test conditions. Hence, recovering waste heat of heavy-duty CNG engines is reasonable because a large part of the fuel combustion power is drained by the exhaust gas and the cooling liquid.

Figure 6. (a) The fuel combustion power of the CNG engine; (b) The effective power output of the CNG engine; (c) The exhaust energy flow rate of the CNG engine; (d) The waste heat flow rate of the engine coolant.
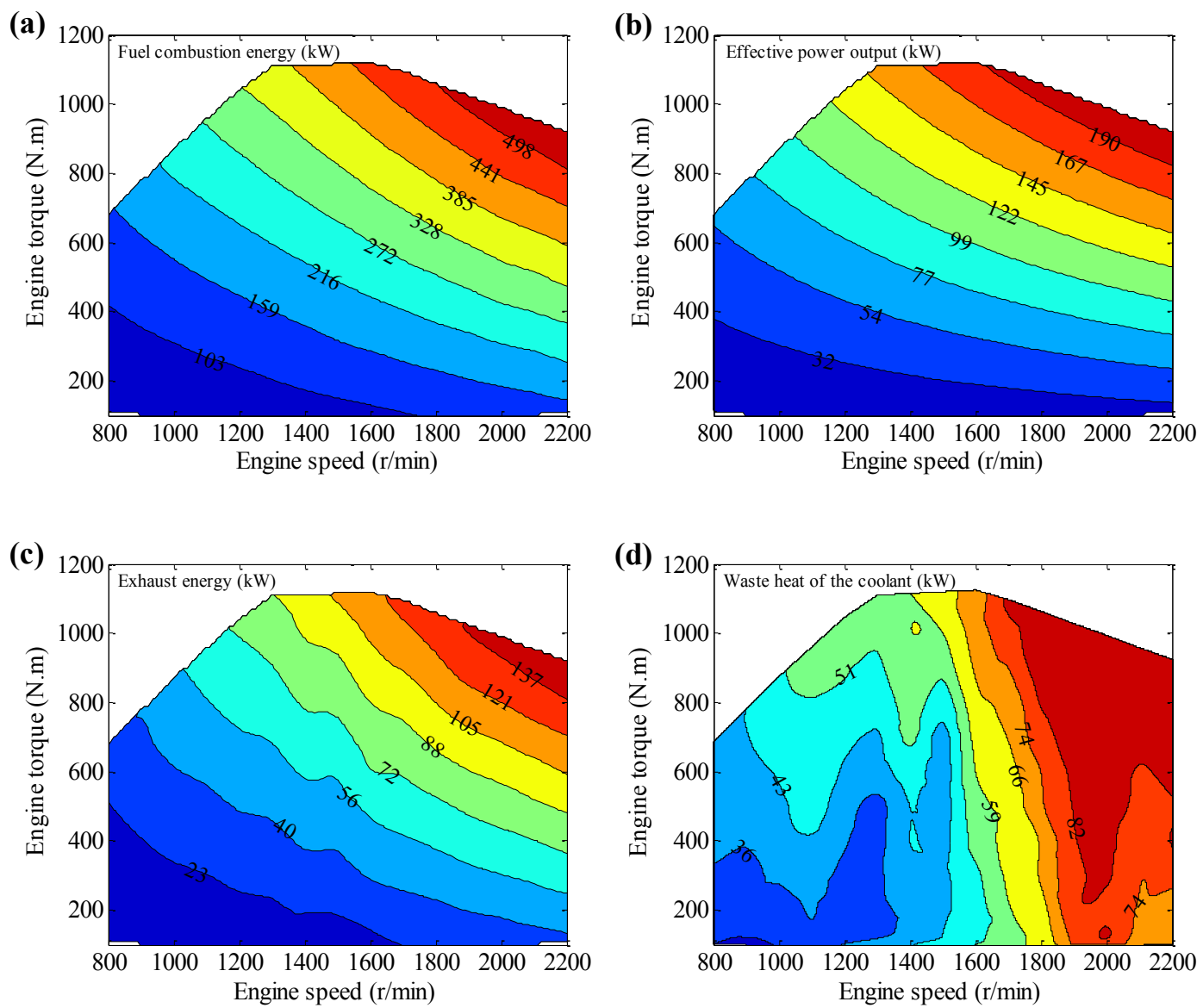

The waste heat energy flow rate of intake air is used to preheat the supercooled working fluid in the LT cycle, and the distributions of several intake air parameters are plotted in Figure 7. As shown in Figure $7 \mathrm{a}$, intake air temperature ranges from 306 to $409 \mathrm{~K}$ in the entire engine test region before it goes into the intercooler. This temperature rises unsteadily as engine speed increases, and then increases stably as engine torque rises. As shown in Figure 7b,c, intake air pressure and air mass flow rate increase monotonously as engine speed and engine torque rise. The maximum intake air mass rate is $0.29 \mathrm{~kg} / \mathrm{s}$ under the rated power output condition. The trend of intake air waste heat power is similar to that of intake air temperature before it enters the intercooler in the entire engine test region, and the maximum value of intake air waste heat is $31.24 \mathrm{~kW}$, which is worth recovering. 
Figure 7. (a) The intake air temperature in the preheater; (b) The intake air pressure in the preheater; (c) The intake air mass flow rate in the preheater; (d) The intake air waste heat flow rate in the preheater.
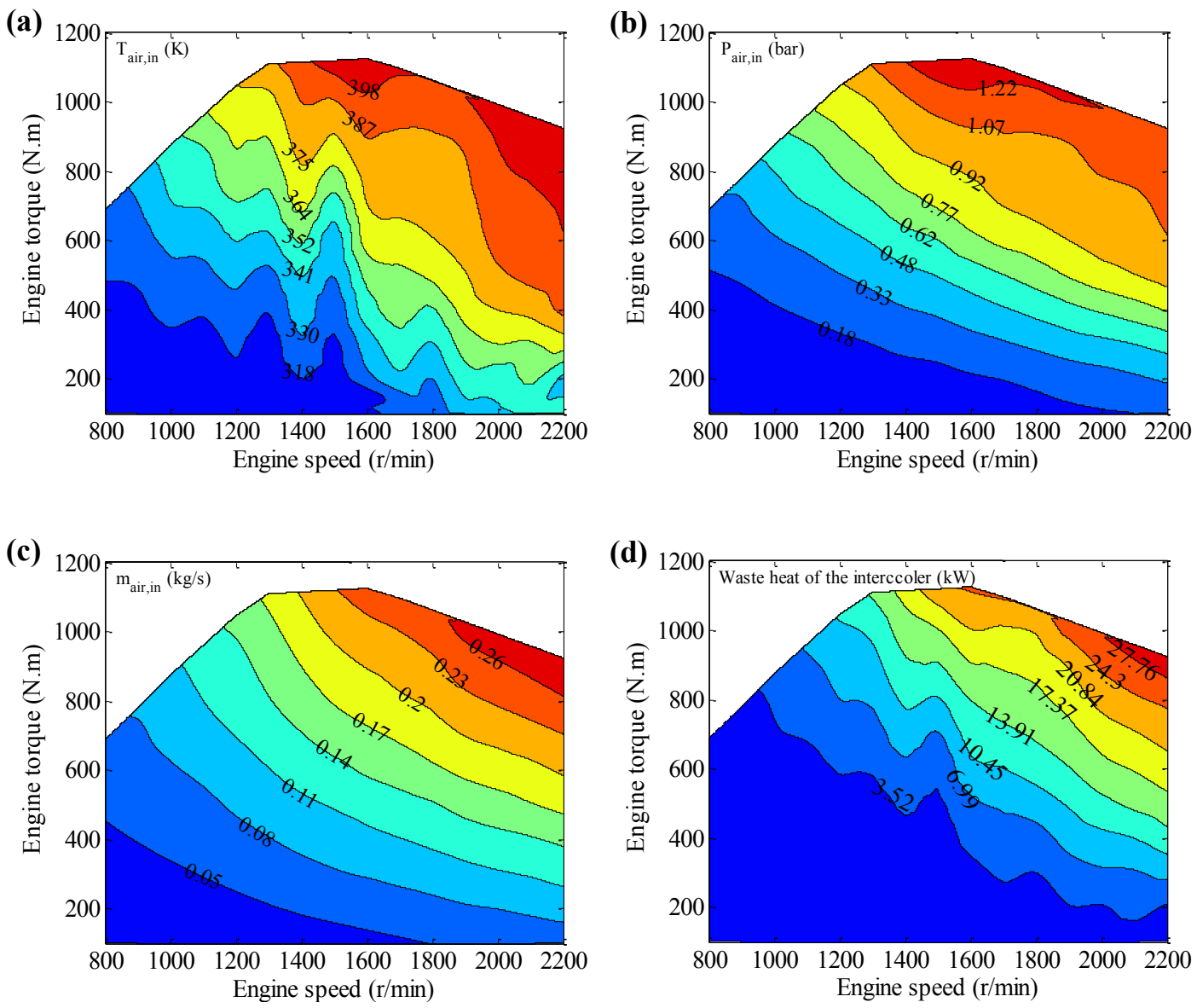

\section{Optimization of the DORC System}

Before the simulation of the performance of the DORC-CNGE combined system, several operating parameters of the DORC system should be settled first according to the waste heat characteristics of the $\mathrm{CNG}$ engine.

In the LT cycle, the condensing temperature of the working fluid is set to $293.15 \mathrm{~K}$, given that the temperature of the cooling water in the condenser is $288.15 \mathrm{~K}$, and an appropriate heat transfer temperature difference between the working fluid and the cooling water should be ensured. The evaporating temperature of the working fluid in the LT cycle is set to $348.15 \mathrm{~K}$ because engine coolant temperature is maintained at near $363.15 \mathrm{~K}$, and an appropriate heat transfer temperature difference between the two fluids should also be ensured. Similarly, the condensing temperature of the working fluid in the HT cycle is set to $353.15 \mathrm{~K}$ according to the evaporating temperature of the working fluid in the LT cycle.

After several operating parameters are settled and the waste heat characteristics of the CNG engine are calculated through the aforementioned equations, the performance of the DORC system is simulated, and the influence of the evaporating temperature in the HT cycle is discussed as follows. Under the rated power output condition of the CNG engine, the relationship between the net power output of the DORC system and the HT cycle evaporating pressure is shown in Figure 8. As shown in 
the figure, the net power output increases rapidly from 21.87 to $29.37 \mathrm{~kW}$ as the evaporating pressure of the HT cycle rises from 1to $3 \mathrm{MPa}$. However, the trend line flattens near the critical evaporating pressure of the HT cycle. When the evaporating pressure is $3.5 \mathrm{MPa}$, the net power output is $29.46 \mathrm{~kW}$, which only slightly increases by $0.09 \mathrm{~kW}$ when the evaporating pressure is $3 \mathrm{MPa}$. Moreover, the working fluid easily decomposes and its characteristics are unstable near the critical pressure area. Hence, setting the evaporating pressure to $3 \mathrm{MPa}$ during simulation is reasonable.

Figure 8. Influence of the evaporating pressure of the HT cycle on the net power output of the DORC system.

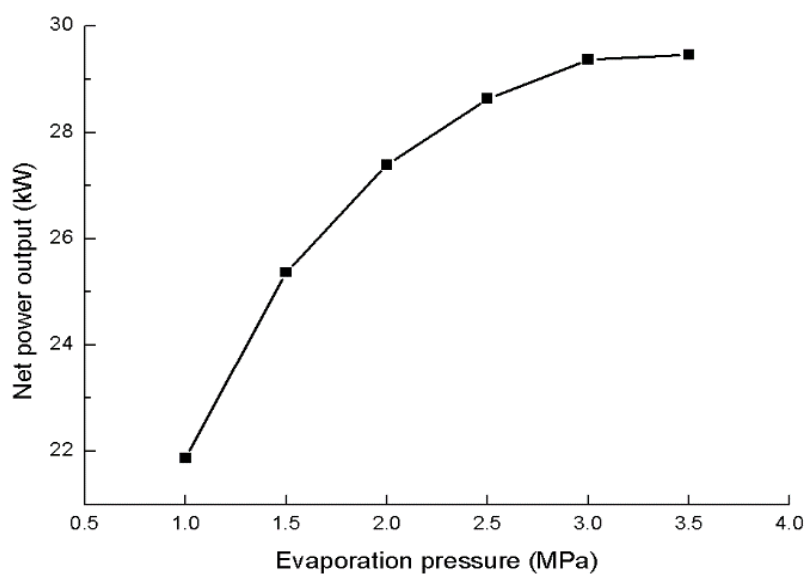

When the evaporating pressure of the working fluid is set to $3 \mathrm{MPa}$, the influence of the superheat degree of the HT cycle working fluid on the net power output of the DORC system is investigated. As shown in Figure 9, as the superheat degree increases from 5 to $20 \mathrm{~K}$, the net power output increases by $0.74 \%$, that is, from 29.61 to $29.83 \mathrm{~kW}$. In addition, the net power output only increase by less than $0.5 \mathrm{~kW}$ compared with the net power output in the saturated state. Moreover, the number of system assemblies and the heat loads of these assemblies increase if the working fluid is heated to the superheated state. Hence, the state of the HT cycle working fluid assumes a saturated state after passing through evaporator 1 in the present work.

Figure 9. Influence of the superheat degree of the HT cycle working fluid on the net power output of DORC system.

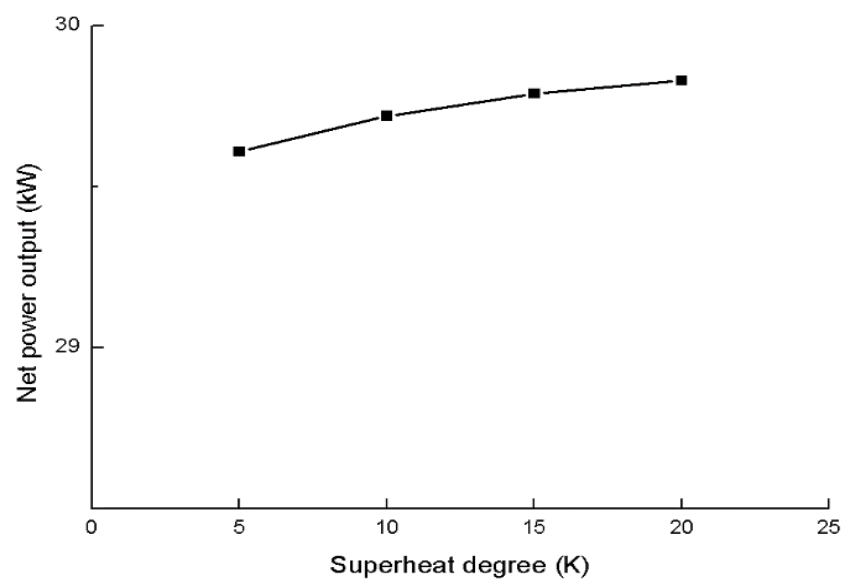




\section{Performance of the DORC-CNGE Combined System}

The performance of the WHR system based on DORC is simulated and discussed for the entire engine test region according to the waste heat characteristics of the $\mathrm{CNG}$ engine and the settled parameters of the DORC system.

As shown in Figure 10, the working fluid mass flow rate and the net power output of the HT cycle exhibit the same trend, which increases as engine speed and engine torque rise, because the net power output of the ORC system is determined by the working fluid mass flow rate when the other parameters of the DORC system are settled in Equations (3), (7), and (28). In the present DORC system, the HT cycle recovers waste heat energy from exhaust gas, and thus, when the amount of exhausted waste heat energy is high, a high value of working fluid flow mass is necessary, and correspondingly, a high net power output is generated. The waste heat energy in exhaust gas, working fluid mass flow rate, and net power output of the HT cycle exhibit the same trends as the engine operating conditions, which vary as shown in Figures $6 \mathrm{c}$ and 10, and the maximum values of the three parameters are $154 \mathrm{~kW}, 0.88 \mathrm{~kg} / \mathrm{s}$, and $10.89 \mathrm{~kW}$, respectively.

Figure 10. (a) The working fluid mass flow rate of the HT cycle; (b) The net power output of the HT cycle.
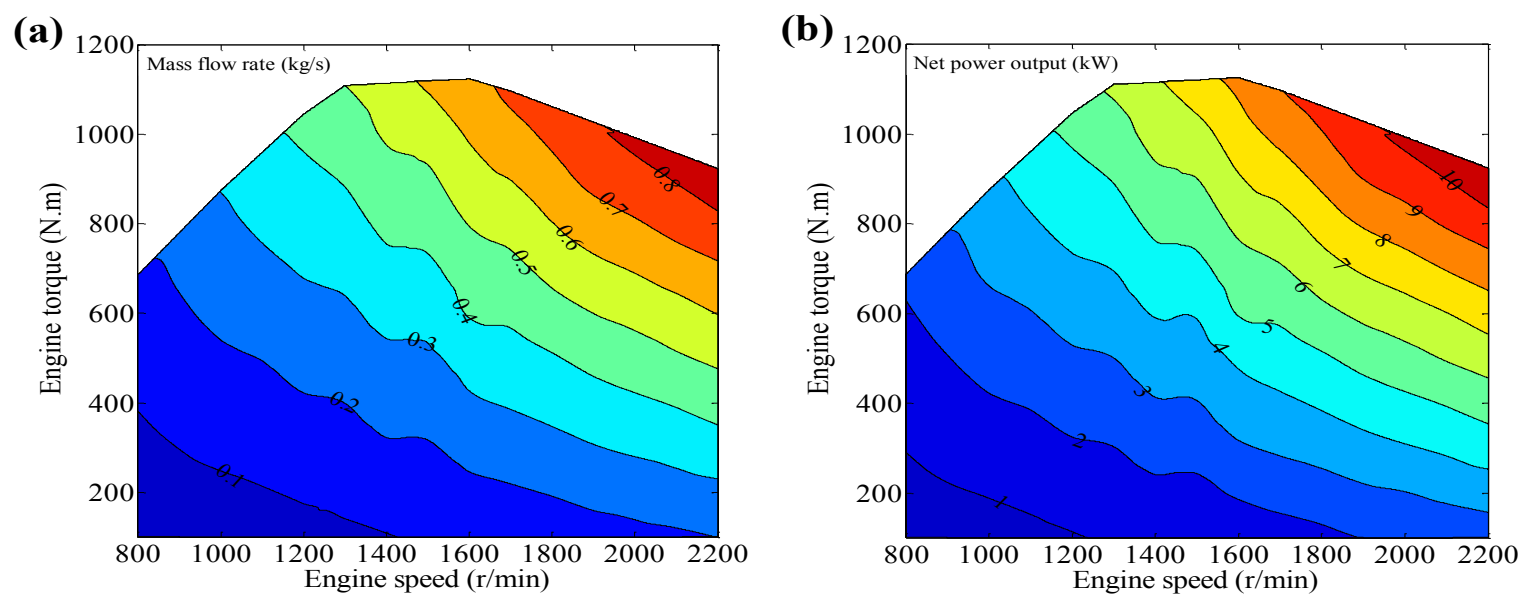

Figure 11 shows the trends of the working fluid mass flow rate and the net power output of the LT cycle versus the engine operating conditions. The two parameters increase as engine speed and engine torque rise. Under the rated engine operating condition, the working fluid mass flow rate and the net power output of the LT cycle reach the maximum values of $0.86 \mathrm{~kg} / \mathrm{sand} 18.48 \mathrm{~kW}$, respectively. Compared with Figures 10a and 11a, the maximum working fluid mass flow rates of the LT and HT cycles lightly differ. However, the maximum net power output of the LT cycle is obviously larger than that of the HT cycle under the same conditions. The main reason for this phenomenon is that the LT and HT cycles have similar working fluid mass rates but the enthalpy difference between the inlet and outlet of expander 2 is obviously larger than that of expander 1.

The distribution of the overall power output of the DORC system within the engine test region is plotted in Figure 12. The overall power output reaches the maximum value of $29.37 \mathrm{~kW}$ under the rated power output condition of the engine, and then increases as engine speed and engine torque rises because the overall power output is the total of the net power outputs of the HT and LT cycles. 
Figure 11. (a) The working fluid mass flow rate of the LT cycle; (b) The net power output of the LT cycle.
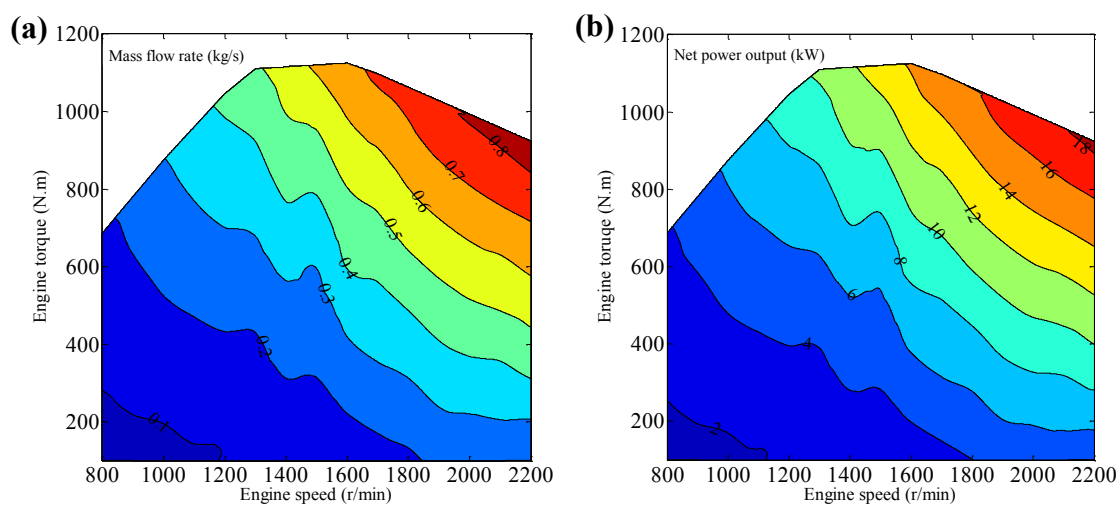

Figure 12. The distribution map of the net power output of the DORC system.

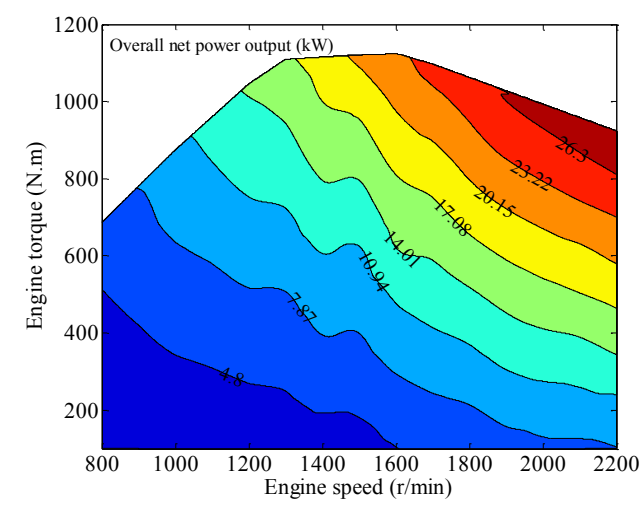

The distribution map of the thermal efficiency of the DORC system under the CNG engine test conditions is shown in Figure 13. As shown in the figure, the thermal efficiency of the DORC system increases as engine speed and engine torque rise under a low engine speed ranging from 800 to $1200 \mathrm{r} / \mathrm{min}$. Moreover, the maximum thermal efficiency within this range is $9.78 \%$ when the engine torque varies from 400 to $700 \mathrm{~N} \cdot \mathrm{m}$. Under medium and high engine speed ranging from 1200 to $2200 \mathrm{r} / \mathrm{min}$, thermal efficiency obviously increases with engine torque, while simultaneously experiencing a slow concussion with engine speed. The maximum thermal efficiency within the entire engine test region reaches up to $10.81 \%$ under the rated power output operating condition of the CNG engine.

Based on the comparison between the DORC-CNGE combined system and the original engine under the $\mathrm{CNG}$ engine test region, the POIR of the DORC-CNGE combined system is calculated, and the results are plotted in Figure 14. Under low torque ranging from 0 to $200 \mathrm{~N} \cdot \mathrm{m}$, the POIR decreases as engine torque obviously increases. However, the POIR increases slowly with engine speed. Under a medium and high torque value of over $200 \mathrm{~N} \cdot \mathrm{m}$, the POIR also decreases as engine torque increases. However, the POIR fluctuates as engine speed reaches $800-1500 \mathrm{r} / \mathrm{min}$, but monotonously increases as engine speed reaches 1500-2200 r/min under medium and high torque ranges. The POIR varies from $13.22 \%$ to $33.73 \%$ under a low torque range, and from $10.41 \%$ to $18.62 \%$ under medium and high torque ranges. Hence, power output is suggested to improve obviously by equipping the DORC system when a CNG-fueled heavy-duty truck runs under highway conditions. 
Figure 13. The distribution map of the thermal efficiency of the DORC system.

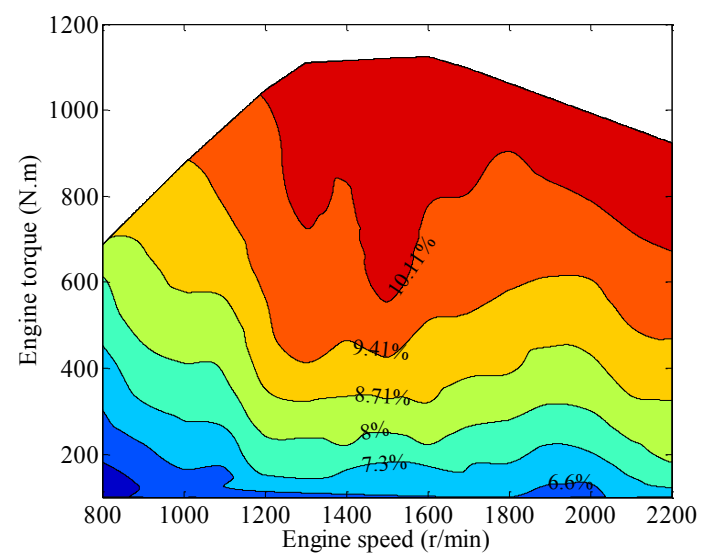

Figure 14. The distribution map of the POIR under the CNG engine test region.

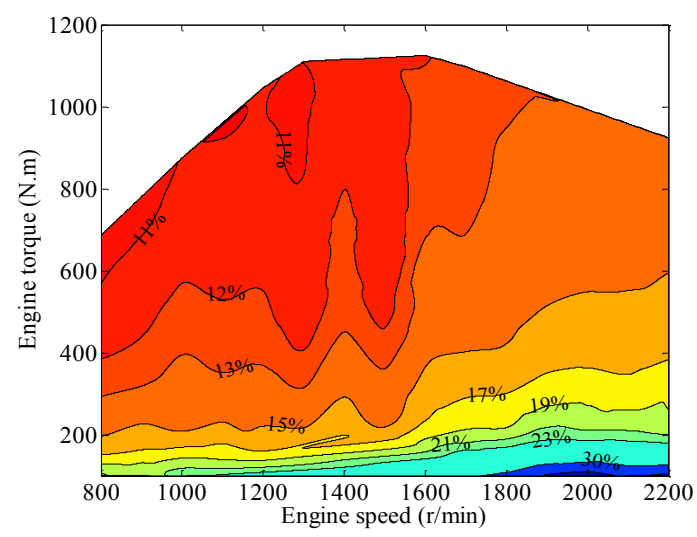

Figure 15 shows the distribution map of the BIR, which is also obtained by comparing the data between the DORC-equipped $\mathrm{CNG}$ engine and the original $\mathrm{CNG}$ engine under the test region. In addition, the BIR exhibits the same trend as the POIR, given that engine operating conditions vary because the increase in power output is equivalent to the BIR, as shown in Equations (35) and (36). The BIR decreases with engine load, and its value is remarkably high $(11 \%-25 \%)$ in low torque operating conditions.

Figure 15. The distribution map of the BIR under the CNG engine test region.

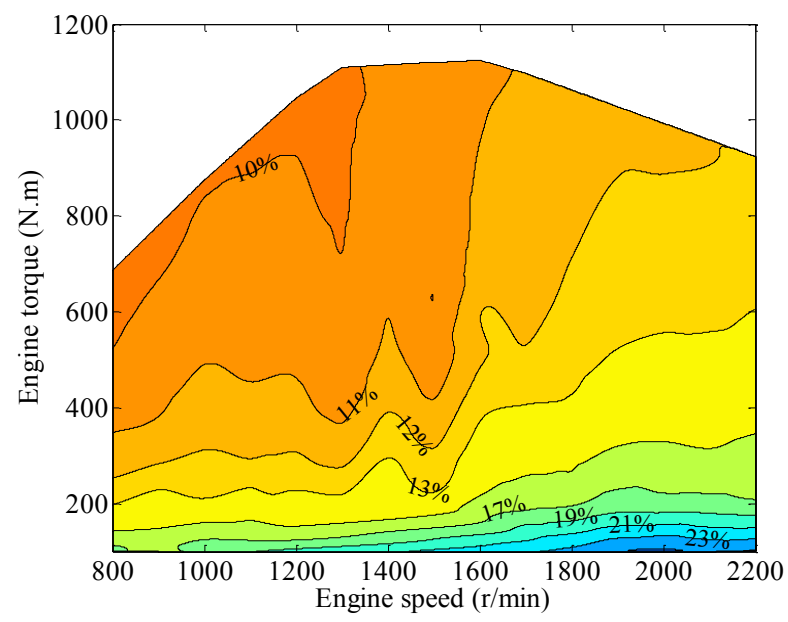


In Figure 16, the exergy destruction rates of the HT cycle components under the rated power output condition of the $\mathrm{CNG}$ engine is shown. Obviously, evaporator 1 has the largest exergy destruction rate, which reaches up to $41.32 \mathrm{~kW}$, because the exhaust gas temperature of the engine is significantly high (generally over $750 \mathrm{~K}$ ), and thus, the temperature difference between the exhaust gas and the working fluid is large and causes huge irreversible losses in evaporator 1. Comparatively, the exergy destruction rates of pump 1, expander 1 , and the preheater are remarkably smaller, that is, $0.73,4.66$, and $2.97 \mathrm{~kW}$, respectively. Optimizing evaporator 1 is seemingly the key to lowering the total exergy destruction rate in the HT cycle.

Figure 16. The exergy destructions rates of components in the HT cycle under the rated power output condition of the CNG engine.

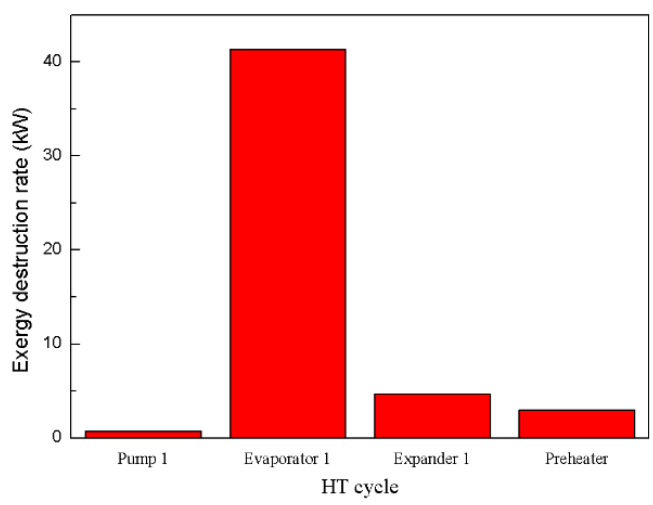

The exergy destruction rates of the LT cycle components under the rated power output condition of the CNG engine is shown in Figure 17. In the LT cycle, the exergy destruction rates of the intercooler, expander 2, and the condenser are relatively high, namely, 4.1, 7.75, and $9.36 \mathrm{~kW}$, respectively. Both the intercooler and the condenser are heat exchangers, whose irreversible loss is determined by the temperature difference between heat exchanges. Meanwhile, the irreversible loss of expander 2 is determined by its isentropic efficiency. Otherwise, the exergy destruction rate of pump 2 is as low as $0.2 \mathrm{~kW}$ because of the small power dissipation of pump 2. The exergy destruction rate of evaporator 2 is only $0.57 \mathrm{~kW}$, given the small irreversible loss in evaporator 2 because of the slight temperature difference between the cooling water and the working fluid in the LT cycle.

Figure 17. The exergy destruction rates of the LT cycle components under the rated power output condition of the CNG engine.

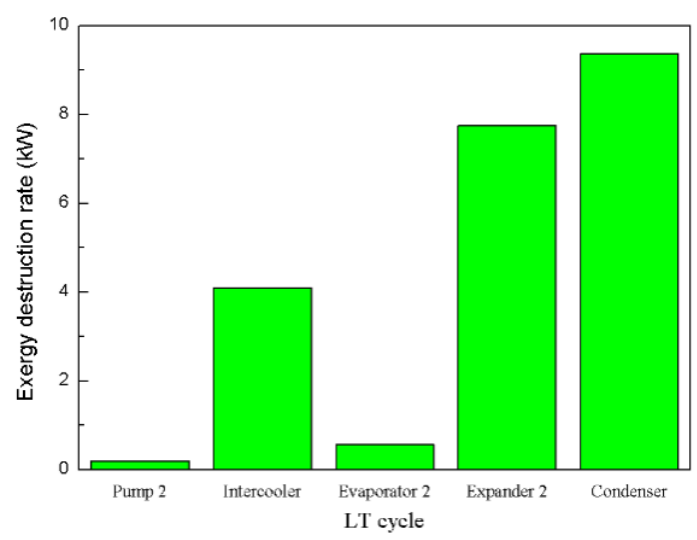


The total exergy destruction rate of the DORC system, the exergy destruction rate of the HT cycle, and the exergy destruction rate of the LT cycle under the entire engine test conditions are shown in Figure 18.

Figure 18. Three kinds of exergy destruction rates of the DORC system under the whole engine test region.

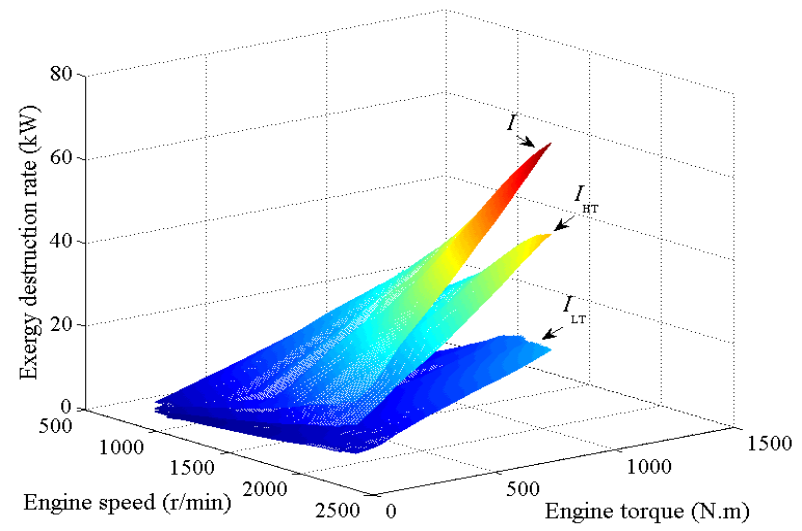

The exergy destruction rates of the HT and LT cycles increase as engine speed and engine load rise. This finding may be attributed to the rise in working fluid mass flow rates of the HT and LT cycles, which is determined by the available waste heat energy. Another reason for this finding is the increase in the irreversible losses of the HT and LT cycles because of the increase in the temperature differences between the heat exchangers. The total exergy destruction rate of the WHR system exhibits the same trend given that it is the total exergy destruction rates of the HT and LT cycles. Under the rated power output of the engine, the maximum exergy destruction rate of the HT and LT cycles are 49.68 and $21.98 \mathrm{~kW}$, respectively, and the maximum total exergy destruction rate is $71.66 \mathrm{~kW}$. Otherwise, the exergy destruction rate of the HT cycle is larger than that of the LT cycle because the exergy destruction rate of evaporator 1 is remarkably larger than those of the other system components according to Figures 16 and 17.

\section{Conclusions}

The WHR system in the present work is designed based on the dual loop ORC for recovering waste heat energy from exhaust gas, intake air, and the engine coolant of the CNG engine. The following conclusions are drawn based on the calculation and analysis of the characteristics of waste heat energy from the $\mathrm{CNG}$ engine and the performance of the DORC system.

(1) The net power output of the LT cycle is larger than that of the HT cycle under most engine test conditions. The maximum values of the net power outputs of the LT and HT cycles, and the overall net power output are $18.48,10.89$, and $29.37 \mathrm{~kW}$, respectively, under the rated power output of the $\mathrm{CNG}$ engine. As the engine runs in low torque ranging for of 0 to $200 \mathrm{~N} \cdot \mathrm{m}$, the POIR varies from $13.22 \%$ to $33.73 \%$, which is remarkably larger than those under medium and high load operating conditions.

(2) The DORC system can improve the fuel economy of the engine. The maximum thermal efficiency of the DORC system is $10.81 \%$ under the rated power output of the engine. The 
BSFC of the DORC-CNGE combined system exhibits an obvious improvement over the original $\mathrm{CNG}$ engine, and the maximum BIR reaches up to $25 \%$ when the $\mathrm{CNG}$ engine runs under the low and medium torque conditions.

(3) The total exergy destruction rate of the DORC system increases with engine speed and engine torque in the entire engine test operating conditions, and the exergy destruction rate of the HT cycle is larger than that of the LT cycle. The maximum exergy destruction rates of the HT and LT cycles are 49.68 and $21.98 \mathrm{~kW}$, respectively.

(4) In both the HT and LT cycles, heat exchangers have relatively high exergy destruction rates, and their optimization is the key to improving the performance of the DORC system.

\section{Acknowledgments}

This work was sponsored by Research Fund for Doctoral Program of Higher Education of China (Grant No. 3C005015201301), National Natural Science Foundation of China (Grant No. 51376011), National Basic Research Program of China (973 Program) (Grant No. 2011CB707202), and Scientific Research Key Program of Beijing Municipal Commission of Education (Grant No. KZ201410005003).

\section{Author Contributions}

Baofeng Yao and Hongguang Zhang meditated this paper. Baofeng Yao, Fubin Yang and Kai Yang carried out the experiment and obtained the engine data. Enhuan Wang and Fubin Yang completed modeling and calculation. Baofeng Yao, Fubin Yang and Hongguang Zhang discussed the results. Baofeng Yao and Fubin Yang wrote the manuscript and all authors read and approve it.

\section{Nomenclature}

$\dot{Q} \quad$ heat transfer rate $(\mathrm{kW})$

$T \quad$ temperature $(\mathrm{K})$

$P \quad$ pressure (MPa)

$\dot{I} \quad$ exergy destruction rate $(\mathrm{kW})$

$b \quad$ Brake specific fuel consumption $(\mathrm{g} / \mathrm{kW} \cdot \mathrm{h})$

$\dot{F} \quad$ fuel mass consumption $(\mathrm{kg} / \mathrm{h})$

\section{Greek Letters}

$c_{\mathrm{p}} \quad$ exhaust specific heat $(\mathrm{kJ} / \mathrm{kg} \cdot \mathrm{K})$

$\varphi \quad$ heat transfer efficiency

\section{Subscript}

$\mathrm{H} 1, \mathrm{H} 2$, $\mathrm{H} 3, \mathrm{H} 4$

state points in the HT cycle

$\begin{array}{cl}\text { p1 } & \text { pump 1 } \\ \text { L } & \text { LT cycle } \\ \text { H } & \text { HT cycle } \\ \text { e1 } & \text { evaporator } 1\end{array}$

HTH high temperature heat source in the HT cycle

$\begin{array}{cl}\dot{W} & \text { power output }(\mathrm{kW}) \\ s & \text { entropy }(\mathrm{kJ} / \mathrm{kg} \cdot \mathrm{K}) \\ h & \text { enthalpy }(\mathrm{kJ} / \mathrm{kg}) \\ \dot{m} & \text { mass flow rate }(\mathrm{kg} / \mathrm{s}) \\ T_{0} & \text { ambient temperature }(\mathrm{K})\end{array}$

$\eta \quad$ efficiency $(\%)$

L1,L2,

L3,L4, state points in the LT cycle L5,L6

p2 pump 2

con condenser

exh exhaust

e2 evaporator 2

in inlet 
LTL low temperature heat source in the LT cycle

HTL high temperature heat source in the LT cycle

exp1 expander 1

exp1 expander 2

net net DORC output

eff effective output of $\mathrm{CNG}$ engines

cs CNG engine-DORC combined system

$\mathrm{CW}$ cooling water in the condenser

$\mathrm{W}$ recovered waste heat energy via the DORC system out outlet

int intercooler

air intake air in the intercooler

HS heat source

pre preheater

eng $\quad \mathrm{NG}$ engine

cool engine coolant

\section{Acronyms}

ORC organic Rankine cycle

CNG compressed natural gas

CNGE compressed natural gas engine

LNG liquid natural gas

DORC dual loop organic Rankine cycle

WHR waste heat recovery

BFSC brake specific fuel consumption

BIR BSFC improvement ratio

POIR power output increase ratio

HT high temperature

\section{Conflicts of Interest}

The authors declare no conflict of interest.

\section{References}

1. Korakianitis, T.; Namasivayam, A.M.; Crookes, R.J. Natural-gas fueled spark-ignition (SI) and compression-ignition (CI) engine performance and emissions. Prog. Energy Combust. Sci. 2011, 37, 89-112.

2. Chacartegui, R.; Sánchez, D.; Muñoz, J.M.; Sánchez, T. Alternative ORC bottoming cycles for combined cycle power plants. Appl. Energy 2009, 86, 2162-2170.

3. Song, J.; Li, Y.; Gu, C.W.; Zhang, L. Thermodynamic analysis and performance optimization of an ORC (Organic Rankine Cycle) system for multi-strand waste heat sources in petroleum industry. Energy 2014, 71, 673-680.

4. Hettiarachchi, H.D.; Golubovic, M.; Worek, W.M.; Ikegami, Y. Optimum design criteria for an organic Rankine cycle using low temperature geothermal heat sources. Energy 2007, 32, 1698-1706.

5. Florian, H.; Markus, P.; Dieter, B. Zeotropic mixtures as working fluids in organic Rankine cycles for low-enthalpy geothermal resources. Renew. Energy 2012, 37, 364-370.

6. Wang, J.F.; Yan, Z.Q.; Zhao, P.; Dai, Y.P. Off-design performance analysis of a solar powered organic Rankine cycle. Energ. Convers. Manag. 2014, 80, 150-157.

7. Tchanche, B.F.; Papadakis, G.; Lambrinos, G.; Frangoudakis, A. Fluid selection for a low-temperature solar organic Rankine cycle. Appl. Therm. Eng. 2009, 29, 2468-2476.

8. Hung, T.C.; Wang, S.K.; Kuo, C.H.; Pei, B.S.; Tsai, K.F. A study of organic working fluids on system efficiency of an ORC using low-grade energy sources. Energy 2010, 35, 1403-1411. 
9. Wang, E.H.; Zhang, H.G.; Fan, B.Y.; Ouyang, M.G.; Zhao, Y.; Mu, Q.H. Study of working fluid selection of organic Rankine cycle (ORC) for engine waste heat recovery. Energy 2011, 36, 3406-3418.

10. Toffolo, A.; Lazzaretto, A.; Manente, G.; Paci, M. A multi-criteria approach for the optimal selection of working fluid and design parameters in Organic Rankine Cycle systems. Appl. Energy 2014, 121, 219-232.

11. Acar, H.I. Second law analysis of the reheat-regenerative Rankine cycle. Energ. Convers. Manag. 1997, 38, 647-657.

12. Mago, P.J.; Chamra, L.M.; Srinivasan, K.; Somayaji, C. An examination of regenerative organic Rankine cycles using dry fluids. Appl. Therm. Eng. 2008, 28, 998-1007.

13. Wang, E.H.; Zhang, H.G.; Fan, B.Y.; Wu, Y.T. Optimized performances comparison of organic Rankine cycles for low grade waste heat recovery. J. Mech. Sci. Technol. 2012, 26, 2301-2312.

14. Srinivasan, K.K.; Mago, P.J.; Krishnan, S.R. Analysis of exhaust waste heat recovery from a dual fuel low temperature combustion engine using an Organic Rankine Cycle. Energy 2010, 35, 2387-2399.

15. Boretti, A. Recovery of exhaust and coolant heat with R245fa organic Rankine cycles in a hybrid passenger car with a naturally aspirated gasoline engine. Appl. Therm. Eng. 2012, 36, 73-77.

16. Wang, T.Y.; Zhang, Y.J.; Zhang, J.; Shu, G.Q.; Peng, Z.J. Analysis of recoverable exhaust energy from a light-duty gasoline engine. Appl. Therm. Eng. 2013, 53, 414-419.

17. Wang, E.H.; Zhang, H.G.; Zhao, Y.; Fan, B.Y.; Wu, Y.T.; Mu, Q.H. Performance analysis of a novel system combining a dual loop organic Rankine cycle (ORC) with a gasoline engine. Energy 2012, 43, 385-395.

18. Zhang, H.G.; Wang, E.H.; Fan, B.Y. A performance analysis of a novel system of a dual loop bottoming organic Rankine cycle (ORC) with a light-duty diesel engine. Appl. Energy 2013, 102, 1504-1513.

19. Gao, W.Z.; Zhai, J.M.; Li, G.H.; Bian, Q.; Feng, L.M. Performance evaluation and experiment system for waste heat recovery of diesel engine. Energy 2013, 55, 226-235.

20. Yu, G.P.; Shu, G.Q.; Tian, H.; Wei, H.Q.; Liu, L.N. Simulation and thermodynamic analysis of a bottoming Organic Rankine Cycle (ORC) of diesel engine (DE). Energy 2013, 51, 281-290.

21. REFPROP Version 8.0, NIST Standard Reference Database 23; The US Secretary of Commerce: Washington, DC, USA, 2007.

22. Bahadori, A. Estimation of combustion flue gas acid dew point during heat recovery and efficiency gain. Appl. Therm. Eng. 2011, 31, 1457-1462.

23. Vaja, I.; Gambarotta, A. Internal combustion engine (ICE) bottoming with Organic Rankine Cycle (ORCs). Energy 2010, 35, 1084-1093.

(C) 2014 by the authors; licensee MDPI, Basel, Switzerland. This article is an open access article distributed under the terms and conditions of the Creative Commons Attribution license (http://creativecommons.org/licenses/by/4.0/). 